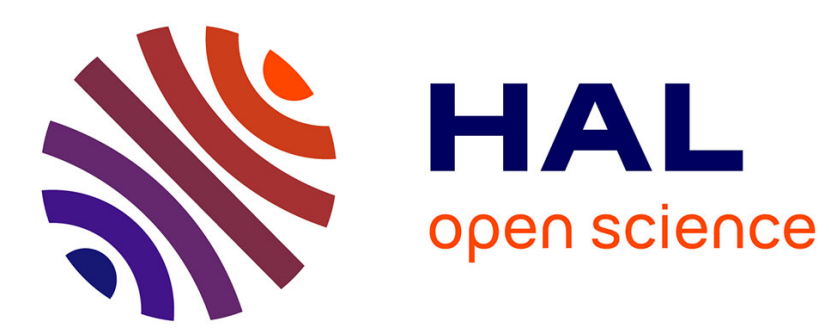

\title{
Fun with Flags and Chemistry
}

Christophe Coudret, Nicolas Dietrich

\section{To cite this version:}

Christophe Coudret, Nicolas Dietrich. Fun with Flags and Chemistry. Journal of Chemical Education, In press, 10.1021/acs.jchemed.0c00514 . hal-02992980

\section{HAL Id: hal-02992980 \\ https://hal.science/hal-02992980}

Submitted on 19 Nov 2020

HAL is a multi-disciplinary open access archive for the deposit and dissemination of scientific research documents, whether they are published or not. The documents may come from teaching and research institutions in France or abroad, or from public or private research centers.
L'archive ouverte pluridisciplinaire HAL, est destinée au dépôt et à la diffusion de documents scientifiques de niveau recherche, publiés ou non, émanant des établissements d'enseignement et de recherche français ou étrangers, des laboratoires publics ou privés. 


\title{
Fun with Flags and Chemistry
}

\author{
${ }_{2}$ Christophe Coudret* and Nicolas Dietrich* \\ Cite This: https://dx.doi.org/10.1021/acs.jchemed.0c00514

3 ABSTRACT: The purpose of this study is to present a learning 4 activity that combines the simultaneous practice of geography and 5 chemistry. It is a game activity based on the identification of 6 national flags and colored molecules (from the famous CPK 7 model), with an extension to the creation of imaginary flags from 8 real, useful molecules for middle school, high school, and university 9 classrooms. The goal of using a game is to motivate/involve 10 learners, to encourage them to work and develop adaptability and 11 responsiveness by practicing chemistry and geography components. 12 The feedback received from students who participated in this 13 exercise during the 2019-2020 academic year has been evaluated 14 and shows an increase of motivation and critical thinking. The 15 objective is to make students more aware of geopolitics, to engage 16 discussion on their awareness of the world, and to prepare them to play an active role in it.

17 KEYWORDS: Humor/Puzzles/Games, Pedagogy, Interdisciplinary/Multidisciplinary, Domain, General Public, Audience, 18 History/Philosophy, Domain, Molecular Properties/Structure, Topics

\section{INTRODUCTION}

20 If we are to face the great challenges of the 21 st century $^{1,2}$ (clean 21 energy, sustainable cities, climate action, good health, etc.), a 22 new approach is required for education. ${ }^{3-5}$ The next generation 23 will have to solve important national or global problems to create 24 the industries and jobs of the future; expand the frontiers of 25 human knowledge about ourselves and the world around us; and 26 tackle important problems related to energy, health, education, 27 the environment, national security, and global development. 28 Interaction between social sciences and natural sciences is a 29 necessary condition for success in this endeavor and an 30 important part of the modernization of the educational process 31 in regard to these challenges. For example, the new technologies 32 and devices that enriched our lives in the 21 st century require 33 rare earth metals. ${ }^{6}$ Future engineering should be sensitive to the 34 planet's natural resources, ${ }^{7}$ their location, the reserves available, 35 and possible substitute products. Therefore, teaching the next 36 generation will require a multidisciplinary approach: ${ }^{8}$ a 37 combination of natural science, technology, innovation, and 38 social science to help them face the challenge of managing the 39 world's resources. Some educators have already developed 40 innovative, multidisciplinary approaches ${ }^{9}$ to teaching geogra41 phy, chemistry, and ecology together, ${ }^{10}$ or combining 42 geography, math, and science to teach climate change and sea 43 level rise. ${ }^{11}$ The results of this research suggest that most 44 students view such developments positively and recognize that 45 they bring many advantages, such as critical thinking and a 46 broadening of their knowledge horizons. ${ }^{12}$ In the perspective of 47 developing a new educative activity in this direction, humanities

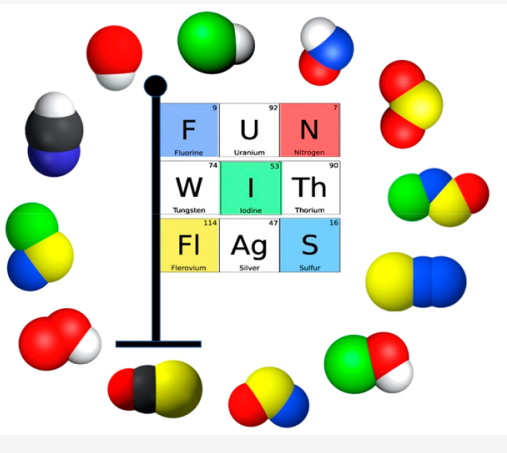

Fun with Flags \& Chemistry:

An educative game for teaching Geography and Science simultaneously and chemistry could be associated, and this paper presents an 48 original, engaging activity to help students to connect chemistry 49 and geography. It was developed on a game based on 50 recognizing flags with simple chemical molecules and is 51 named "Fun with Flags" in reference to episode 14 of the fifth 52 season of The Big Bang Theory, ${ }^{13}$ an American television sitcom 53 created by Chuck Lorre and Bill Prady in 2007, where two of the 54 main characters present a YouTube podcast on the topic of 55 vexillology $^{14}$ (term created by Whitney Smith in 1958 from the 56 Latin word vexillum/"flag" and the Greek suffix -logia /"study") 57 named "Sheldon Cooper Presents: Fun With Flags". In this 58 fictional video podcast, several "fun facts" about flags, such as the 59 shape, the presence of animals, or the origins of the flags, are 60 presented in an entertaining way. Using pop-culture refer- 61 ences $^{15-18}$ is an interesting approach to improve students' 62 motivation, ${ }^{17}$ and several educators have developed educational 63 games $^{19-22}$ to involve students in interactive, entertaining 64 activities. ${ }^{23}$ Games are an excellent method of active learning in a 65 recreational environment, ${ }^{24}$ and many methods have been 66 tested in the past decade: ${ }^{25}$ a word game, ${ }^{26}$ quiz games, ${ }^{27-35} 67$ card games, ${ }^{36-38}$ dice games, ${ }^{39,40}$ board games, ${ }^{41-46}$ computer 68 games, $^{47-49}$ memory/concentration games, ${ }^{50-52}$ and even 69

Received: May 24, 2020

Revised: September 19, 2020 
(a)

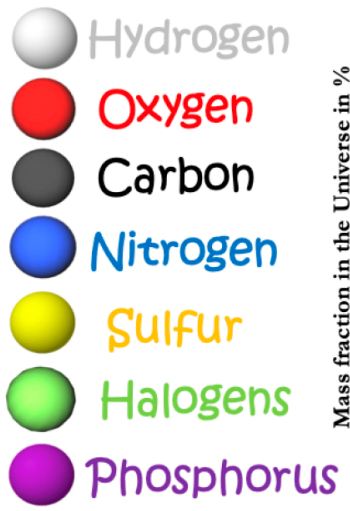

(b)

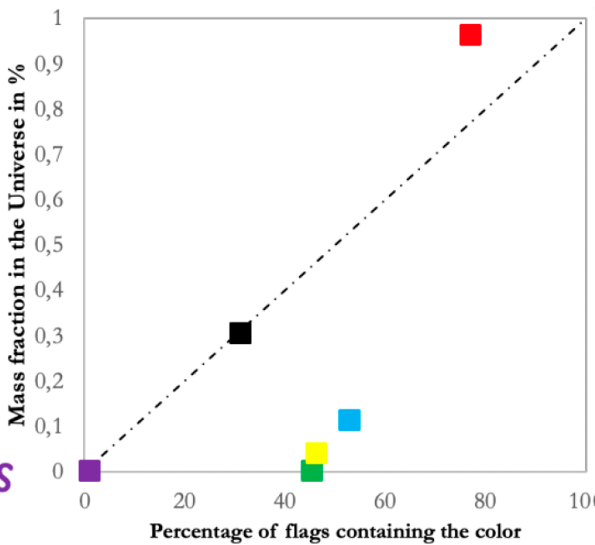

(c)

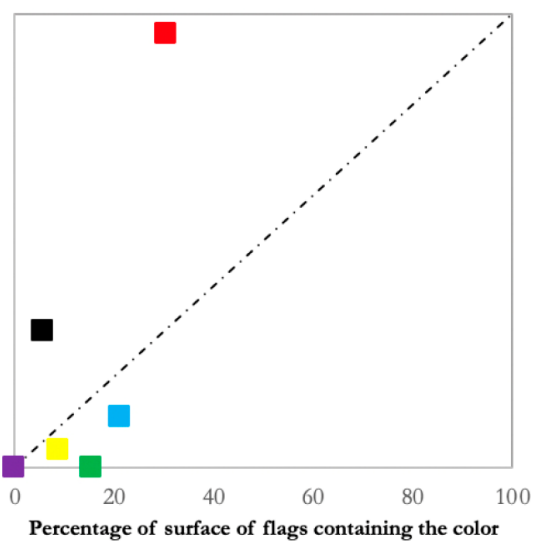

Figure 1. (a) CPK model. (b) Mass fraction in the universe in \% plotted against the percentage of flags containing the color. (c) Representation of the atom fraction in parts per million in the universe plotted against the percentage of flags containing the color (refs 73 and 74 ). Hydrogen mass fraction in the universe is $70.57 \%$, and white is present in $72.92 \%$ of flags and in $19.12 \%$ of the surface.

70 escape games. ${ }^{53-58,58-61}$ All of these educators have succeeded 71 in creating a recreative environment improving the student's 72 engagement and motivation for science.

73 The link between flags and chemistry has already been 74 attempted by educators, only on the basis of the chemistry 75 necessary to produce the colored dyes. ${ }^{62}$

76 Some authors have tried to connect objects with molecules in 77 order to create a recreative environment, such as structural 78 chemical formulas with human forms (called NanoPurtians), ${ }^{63}$ 79 monsters (NanGobelin), ${ }^{64}$ or racing car shapes. ${ }^{65,66}$ The goal of 80 these studies was to educate children in the sciences in an 81 effective and enjoyable manner. They have made several videos 82 featuring the NanoPutians as anthropomorphic animated 83 characters. In order to relate vexillology with chemistry, and in 84 the following of these chemistrymorphisms, we propose to create 85 a game on the manipulation of colored atoms looking like the 86 real flags. In 1952, Corey and Pauling published a description of 87 space-filling models of proteins and other biomolecules that they 88 had been building at Caltech. ${ }^{67}$ Their models represented atoms 89 by faceted hardwood balls, painted in different colors to indicate 90 the component chemical elements. Their color scheme included 91 the following: white for hydrogen, black for carbon, blue for 92 nitrogen, and red for oxygen (Figure 1a). In 1965, Koltun 93 patented $^{68}$ an improved version of the Corey and Pauling 94 modeling technique. In his patent, he added several colors: 95 yellow for sulfur, purple for phosphorus, green for the halogens 96 (F, Cl, Br, I), and silver for metals. This model is known as the $97 \mathrm{CPK}$ model (for Corey, Pauling, and Koltun). Several of the $98 \mathrm{CPK}$ colors refer mnemonically to colors of the pure elements or 99 notable compounds (hydrogen is a colorless gas; carbon, as 100 charcoal, graphite, or coke, is black; sulfur powder is yellow; 101 chlorine is a greenish gas; etc.). This molecular model is typically 102 used by students in introductory organic chemistry courses to 103 represent bonds and atoms with small plastic polygons or 104 spheres, ${ }^{69,70}$ and the models are helpful when students are 105 learning about molecular geometry and stereochemistry. This 106 paper describes an activity to link national flags to simple 107 chemical molecules of the same color (according to the CPK 108 code) in order to make students manipulate geography and 109 chemical concepts simultaneously. This activity can be done 110 remotely for distance learning ${ }^{7,54,60,71}$ from middle school to university level (with an adaptation of the discussion, see the 111 Discussion section).

\section{RELATIONSHIP BETWEEN FLAGS AND THE CPK MODEL}

There are numerous flags in the world, representing the different 115 geographical, ethnic, religious, and national groups of human- 116 kind. A flag is more than an image or a scrap of fabric, it can be a 117 part of an individual's identity and a visual representation of a 118 collective. According to the United Nations, there is a total of 119 193 sovereign states in the world (and 2 observers states), and 120 each one has a recognizable national flag. ${ }^{72}$ The most frequent 121 type is the three-colored flag ( $40 \%$ of flags), followed by two- 122 and four-colored flags (20\% each).$^{73}$ Red is the most widely used 123 color by percentage surface area and by number of flags (Figure 124 1b). The second color in the ranking is not the same by area and 125 by frequency (blue or white), as shown in Figure lb,c. It is 126 noteworthy that the colors originally chosen for the CPK model 127 are very similar to the colors present in the flags of the world's 128 nations.

It is also worth noting that there is a similarity in value for 130 some colors/atoms between the presence in flags and presence 131 in the universe. For example, the hydrogen atom (white in the 132 CPK model) is present at $70.57 \%$ in the universe and appears in 133 $72.92 \%$ of the flags while the phosphorus atom (purple) is 134 present at less than $0.1 \%$ in the universe or in national flags 135 (purple is used only in the flags of Spain, Nicaragua, and Sri 136 Lanka and in a small proportion). This demonstrates a good 137 probability of identifying flags and molecules with the same 138 colors. The only exception is for the color orange, which is not 139 included in the original CPK model but is present in $4.6 \%$ of 140 flags (1.2\% of surface area), excluding flags of Ireland, India, 141 Côte d'Ivoire, and a few other countries from our analysis. In 142 vexillology there are many geometrical flag designs: cantons (a 143 flag divided in four equal quarters), pales (a flag divided into 2 or 144 3 vertical bands), fesses (a flag divided into three horizontal 145 bands), saltire (a flag with a diagonal cross), and Scandinavian 146 cross (a flag with a cross, the vertical arm of which is positioned 147 more toward the hoist). Two thirds of all national flags include 148 the use of symbols (sometimes even more than one) such as a 149 star $(30 \%)$, emblem (14\%), cross (9\%), sun (8\%), or crescent 150 (7\%). Most flags are based on a simple formula of colors, 151 
152 symbols, and layouts, and this results in as many differences as 153 surprising similarities. 53\% of all national flags are designed with 154 a simple band layout, and the three-stripe design is by far the 155 most popular, with over 80 national flags. The most widely used 156 combinations are red-blue-white ( 30 flags), red and white (16 157 flags), green-white-red (12 flags), red-yellow-white (11 158 flags), and white-blue (10 flags).

\section{METHODOLOGY}

160 Students from two separate courses used the game activity as a 161 homework project after attending a series of lectures $(10 \mathrm{~h})$ 162 covering an introduction to chemistry. The 87 students who 163 participated came from either a Chemical Engineering course 164 (class 1, 56 students, in 2020) or an Introduction to Chemistry 165 master course (class 2, 31 students, in 2020). At the end of the 166 activity, the teacher invited all students to evaluate the activities 167 by completing an online form in French containing 10 questions 168 with responses based on the Likert ${ }^{75}$ scale. Participants were 169 approached twice by email, and the response rate was $80 \%$. The 170 data from the online surveys were entered into a Microsoft Excel 171 spreadsheet and were collated. All responses were analyzed, and 172 the results are presented in the next section.

\section{$173 \square$ ACTIVITY}

174 The core of the activity is based on quizzes concerning the 175 identification of the country from a simple molecule 176 representing the associated flag. The objectives of the activity 177 are to make student practice the CPK model (memorizing color 178 and atoms), to manipulate the molecular geometry (VSEPR 179 theory), and also to initiate discussions on resource localization 180 and geopolitics and culture and history. We will first restrict the 181 activity to band type flags with one to four colors in order to 182 propose perfect matching or quasiperfect matching between the 183 flags and chemical molecules of $1-4$ atoms, and we will neglect 184 all the symbols (emblem, cross, coat of arms, etc.) or differences 185 in shape ratio to simplify the problem. After what was, to the best 186 of our knowledge, a complete analysis of all national flags, we 187 found only 10 "perfect matches" between existing flags and 188 existing chemical compounds, with the right color, the right 189 order of the colors, and the correct number of colors ( 4 for 190 bicolor flags, and 6 for tricolor flags) and 20 quasiperfect 191 matches (where the colors were correct but not the number of 192 colors or the order of the colors). Figure 2 depicts the 10 "perfect 193 matches": from left to right, the flags are Gabon (Figure 2a, it 194 could also work for Rwanda in the reverse order), Estonia 195 (Figure 2b), Monaco/Indonesia/Singapore (Figure 2c; it could 196 work for Poland in the reverse order), Algeria (Figure 2d; it 197 could also work for Pakistan in the reverse order and Wales with 198 a rotation), Russia/Slovakia/Slovenia (Figure 2e), Spain 199 (Figure 2f), Romania/Moldavia/Chad (Figure 2g), Belize 200 (Figure 2h), Nigeria (Figure 2i), and Portugal (Figure 2j; it 201 could also work for Burkina Faso with a $90^{\circ}$ rotation). The 202 molecules used to recreate the flags are given in the legend of the 203 figure.

204 This first series of flags is considered as easy due to the perfect 205 match of color/order/number of colors between a flag and its 206 CPK representation. It allows a total of 16 countries to be 207 manipulated (depending on the orientation of the molecule). 208 This series provides a good introduction to the activity and 209 permits a focus on the similarity of certain flags in the world.

210 The second series concerns quasiperfect matching, where the 211 number of atoms and their colors are identical to the number of

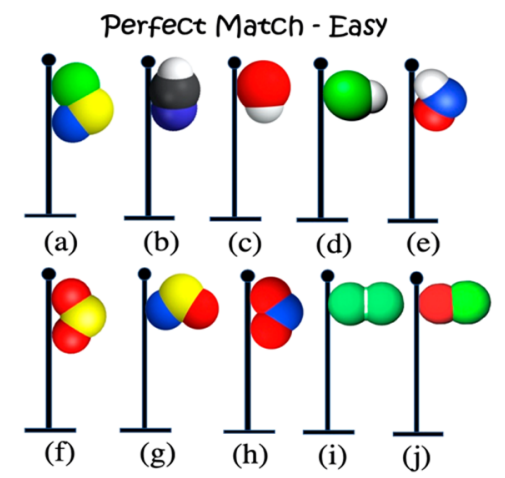

Band Flag: Color $\checkmark$ Order $\checkmark$ Number $\checkmark$

Figure 2. Molecular flags built with the CPK model for (a) Gabon/ Rwanda-ClNS thiazyl chloride; (b) Estonia-HCN hydrogen cyanide; (c) Monaco/Indonesia/Singapore- $-\mathrm{OH}^{-}$hydroxide; (d) Algeria-HCL hydrochloric acid; (e) Russia/Slovakia/SloveniaHNO nitroxyl; (f) Spain-OSO sulfur dioxide; (g) Romania/Chad/ Moldavia/Andorra-OSN ${ }^{-}$sulfinylazanide; (h) Belize $-\mathrm{NO}_{2}{ }^{-}$nitrite; (i) Nigeria $-\mathrm{HF}_{2}^{-}$bifluoride; (j) Portugal- $\mathrm{ClO}^{-}$hypochlorite.

bands and the colors of an existing flag, but not the order. The 212 difficulty is thus greater than in the first series. Figure 3 depicts $5213 \mathrm{f} 3$

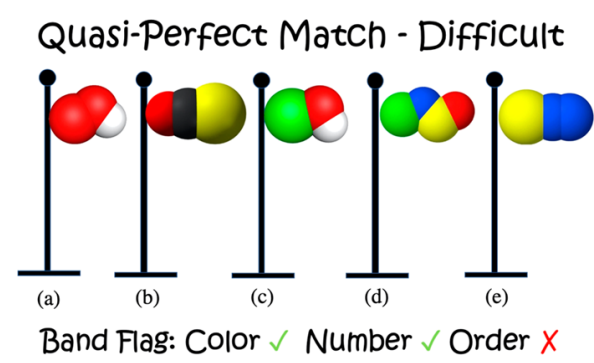

Figure 3. Molecular flags built with the CPK model for: (a) Austria/ Peru-OHO hydroperoxyl; (b) Belgium/Germany-OCS carbonyl sulfide; (c) Bulgaria/Italy/Hungary/Iran/Mexico/Tajikistan-HClO hypochlorous acid; (d) Mauritius-CINOS sulfinylamino chloride; (e) Barbados $-\mathrm{N}_{2} \mathrm{~S}$ dinitrogen- $N$-sulfide.

"quasiperfect matches”. From left to right, the flags are Austria/ 214 Peru (Figure 3a), Belgium/Germany (Figure 3b), Bulgaria/ 215 Italy/Hungary/Iran/Mexico/Tajikistan (Figure 3c), Mauritius 216 (Figure 3d), and Barbados (Figure 3e). The molecules used to 217 recreate the flags are given in the legend of the figure. 218

Note that "perfect match" flags could also be used for 219 "quasiperfect" matching: Figure 2 e could be used in that context 220 for the flags of France/Netherlands/Luxemburg/Croatia/ 221 Czech Republic, and Figure 2e could be used for the flags of 222 Colombia/Ecuador/Armenia/Venezuela. This second series of 223 flags allows a total of 20 supplementary countries to be 224 manipulated. The difficulty is higher due to the fact that colors 225 are not in the right order, but as there is often more than one 226 solution for each molecule, the possibility of success is good. The 227 third series proposed concerns the "imperfect matches" where 228 the color of the flags and the molecules are the same, but the 229 order or the number of colors are not correct, making this 230 category the hardest one. Figure 4 depicts the 17 "imperfect $231 \mathrm{f} 4$ matches". Starting with the band flag, at the top, from left to 232 right: Somalia (Figure 4a), Argentina/Salvador/Guatemala/ 233 Honduras/Israel (Figure 4b), Vatican (Figure 4c), Bolivia/ 234 Lithuania/Cameroon/Republic of the Congo/Guinea/Mali/ 235 Senegal/Ethiopia/Myanmar (Figure 4d), Sierra Leone/Uzbeki- 236 


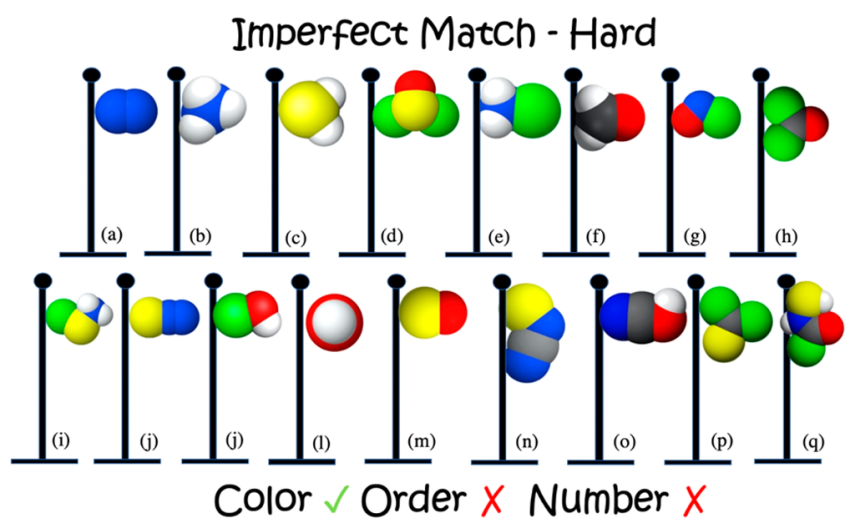

Figure 4. Molecular flags built with the CPK model for (a) Somalia$\mathrm{N}_{2}$ nitrogen; (b) Argentina/Salvador/Guatemala/Honduras/Israel$\mathrm{NH}_{3}$ ammonia; (c) Vatican- $\mathrm{H}_{2} \mathrm{~S}$ hydrogen sulfide; (d) Bolivia/ Lithuania/Cameroon/Republic of the Congo/Guinea/Mali/Senegal/ Ethiopia/Myanmar- $\mathrm{Cl}_{2} \mathrm{OS}$ thionyl chloride; (e) Sierra Leone/ Uzbekistan/Lesotho- $\mathrm{NH}_{2} \mathrm{Cl}$ chloramine; (f) Yemen/Egypt/Syria/ Iraq- $\mathrm{CH}_{2} \mathrm{O}$ formaldehyde; (g) Azerbaijan-ClNO nitrosyl chloride; (h) Malawi/Afghanistan/Libya- $\mathrm{CCl}_{2} \mathrm{O}$ phosgene; (i) Brazil$\mathrm{H}_{2} \mathrm{ClNS}$ amino thiohypochlorite; (j) Ukraine/Congo/European Union/Kazakhstan/Sweden- $\mathrm{N}_{2} \mathrm{~S}$ dinitrogen- $\mathrm{N}$-sulfide; (k) Oman$\mathrm{HClO}$ hypochlorous acid; (l) Turkey/Tonga/Switzerland/Tunisia/ Japan/Denmark/Canada/Bahrein $\mathrm{OH}^{-}$hydroxide; (m) China/ Kyrgyzstan/North Macedonia/Vietnam-SO sulfur monoxide; (n) Bahamas- $\mathrm{CN}_{2} \mathrm{~S}$ thiocyanamide; (o) South Korea-CHNO cyanic acid; (p) Jamaica- $\mathrm{CCl}_{2} \mathrm{~S}$ thiophosgene; (q) South Africa/Olympic Flag- $\mathrm{CH}_{2} \mathrm{ClNOS} \mathrm{N}$-sulfanylcarbamoyl chloride.

237 stan/Lesotho (Figure 4e), Yemen/Egypt/Syria/Iraq (Figure 238 4f), Azerbaijan (Figure 4g), and Malawi/Afghanistan/Libya 239 (Figure 4h, which also works for the Pan-African flag). This 240 series adds more than 27 countries, to give a total of 64 (triband 241 flags that can be linked to a simple chemical molecule with 242 several levels of difficulty).

243 In order to complete the analysis with nonband flags, 244 including all the elements present in the flag this time, some 245 other shapes are presented in Figure 4: at the bottom, from left 246 to right, Brazil (Figure 4i), Ukraine/Congo/Kazakhstan/ 247 Sweden (Figure 4j, which also works for the European Union $248 \mathrm{flag}$ ), Oman (Figure 4k), Turkey/Tonga/Switzerland/Tunisia/ 249 Japan/Denmark/Canada/Bahrein (Figure 41), China/Kyrgyz$250 \mathrm{stan} /$ North Macedonia/Vietnam (Figure 4m), Bahamas (Figure $2514 n$ ), South Korea (Figure 4o), Jamaica (Figure 4p), and South 252 Africa (Figure 4q, which also works for the Olympic flag). This 253 last series, which adds 23 extra countries, is more complicated to 254 solve due to the complexity of certain flags such as those of Brazil 255 or South Africa. A full table is proposed in the Supporting 256 Information in order to list all the combinations of color possible 257 with simple molecules for the 186 states of the United Nations. 258 Another series of flags is also proposed. It is the most difficult 259 one, based on flags that no longer exist. For this section, special 260 attention has been paid to unicolor flags, which is open to 261 discussion for specific molecules. This category implies 262 matching the flag with a homonuclear molecule (molecule 263 composed of only one type of element). The most familiar 264 homonuclear molecules are diatomic (they consist of two 265 atoms): hydrogen $\left(\mathrm{H}_{2}\right)$, oxygen $\left(\mathrm{O}_{2}\right)$, nitrogen $\left(\mathrm{N}_{2}\right)$, and all the 266 halogens (an easy-to-remember mnemonic for the diatomic 267 elements is "Have No Fear Of Ice Cold Beer" for hydrogen, 268 nitrogen, fluorine, oxygen, iodine, chlorine and bromine). 269 Ozone $\left(\mathrm{O}_{3}\right)$ is a triatomic homonuclear molecule and phosphorus $\left(\mathrm{P}_{4}\right)$ a tetratomic molecule. Allotropes are different 270 chemical forms of the same element (not containing any other 271 element) that are homonuclear: sulfur forms several allotropes 272 containing different numbers of sulfur atom $\left(\mathrm{S}_{2}, \mathrm{~S}_{3}, \mathrm{~S}_{6}, \mathrm{~S}_{8}\right) 273$ forms. The element carbon is known to have several 274 homonuclear molecules, including diamond and graphite. 275 With these particular molecules, it is possible to establish 276 single-color flags. Although no monocolor flags exist at the 277 present time, there have been several in the past, as presented 278 with the last series of flags in Figure 5.

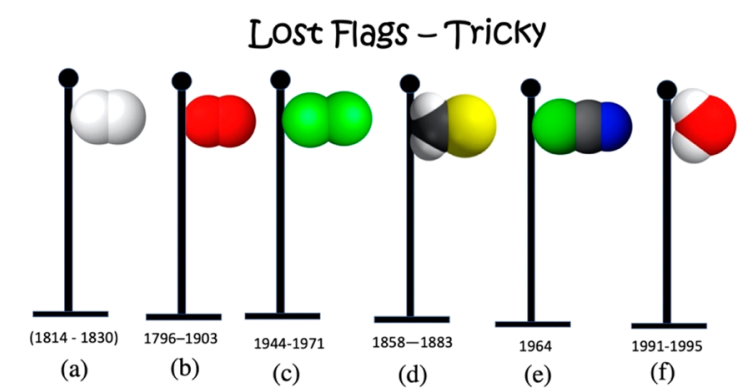

Figure 5. Molecular flags built with the CPK model for: (a) Kingdom of France (1814-1830) - $\mathrm{H}_{2}$ hydrogen; (b) Maldives (1796-1903)$\mathrm{O}_{2}$ oxygen; (c) Libya (1944-1971) - $\mathrm{Cl}_{2}$ chlorine; (d) Russian Empire (1858-1883) $-\mathrm{CH}_{2} \mathrm{~S}$ thioformaldehyde; (e) Zanzibar (JanuaryApril 1964)—CCIN cyanogen chloride; (f) Belarus (1991-1995)$\mathrm{H}_{2} \mathrm{O}$ water.

Figure 5 depicts the 5 "lost flags", starting with the monocolor 280 flags: from left to right, the flag of the former Kingdom of France 281 (1814-1830) in Figure 5a (it could also work for the flag of 282 peace or surrender), the former flag of the Maldives (1796- 283 1903 ) in Figure $5 \mathrm{~b}$ (this flag could also be used as an imperfect 284 match for Morocco), the former flag of Libya (1944-1971) in 285 Figure 5c, the band flag of the former Russian Empire (1858- 286 1883) in Figure 5d, the former flag of Zanzibar (January-April 287 1964) in Figure 5e, and the former flag of Belarus (1991-1995), 288 the last two of which are also perfect matches. This last series 289 enables the student to manipulate specific homonuclear 290 molecules and may also lead on to a discussion on the effect 291 of political events and regime changes (royalty to democracy) 292 that could lead to a change of the national flag. This last series 293 also provides the opportunity to manipulate well-known 294 molecules such as water $\left(\mathrm{H}_{2} \mathrm{O}\right)$, which is one of the most 295 famous molecules in the world. In order to encompass as many 296 of the known molecules as possible, a last series is proposed. In 297 this series, it is not the molecule that is represented but a fictional 298 flag created on the basis of an existing well-known molecule. The 299 8 imaginary flags that can be found are depicted in Figure 6 and $300 \mathrm{fo}$ complete the list of famous molecules already used in the 301 previous series $(\mathrm{HCl}, \mathrm{HCN}, \mathrm{HClO}$, etc.).

These molecules can lead to a specific discussion on the 303 complex shapes of flags and specific elements of vexillology 304 (stripes, triangle, circle) and introduce the rare color purple. 305 Discussion of the production of each molecule and the 306 production locations in real countries is also possible. CPK 307 colors are concentrated in the nonmetal part of the periodic 308 table. To achieve brightly colored edifices, one should then 309 imagine combinations with this restricted group of elements. 310 This can lead to an interesting exploration of chemical literature: 311 are such combinations stable? When have they been prepared? 312 What for? What are their properties? 


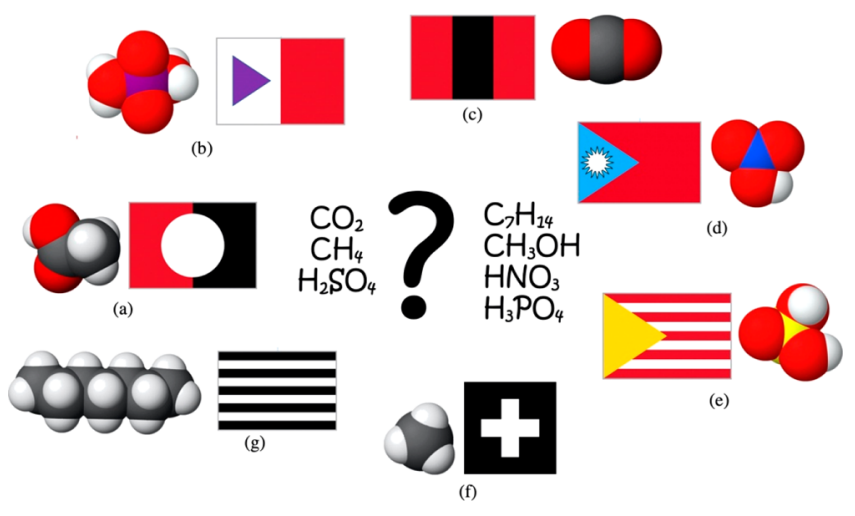

Figure 6. Imaginary flags built with the $\mathrm{CPK}$ model from real molecules: (a) $\mathrm{CH}_{3} \mathrm{OH}$ - methanol; (b) $\mathrm{H}_{2} \mathrm{PO}_{4}$ - phosphoric acid; (c) $\mathrm{CO}_{2}$ - carbon dioxide; (d) $\mathrm{HNO}_{3}$ - nitric acid; (e) $\mathrm{H}_{2} \mathrm{SO}_{4}$ - sulfuric acid; (f) $\mathrm{CH}_{4}$-methane (g); $\mathrm{C}_{7} \mathrm{H}_{14}$-heptane.

\section{DISCUSSION}

315 From all of these series of flags, simple quizzes could be 316 organized with the students, where the objective is to find what 317 molecule and what country (or countries) is (are) represented 318 by each molecular flag. Some variations could be done to adapt 319 the level of the activity from middle school to university such as 320 letting (or not) the students have access to a database of flags in 321 order to find the most difficult ones and even to an encyclopedia 322 to identify flags from earlier times (see the Supporting 323 Information). Teachers can let each student draw a molecule 324 at random and let them find the corresponding flag, and the 325 different characteristics of the country, and of the molecule. 326 After the game, questions can be raised, based on the 327 identification of capitals, continents, and the molar weight or 328 the applications of the chemical compounds. It is also an 329 opportunity to address the question of resources and its 330 localization and about the gross domestic product (GDP) of 331 each country. Moreover, combined questions can be elaborated 332 such as "In which continent is Thiophosgene?" (Thiosphosgene 333 is Jamaica; answer is "america"), "What is the most Belgian 334 molecule?" (answer is "carbonyl suflide"), "Propose an existing 335 molecule with the most common color combination (and name 336 the country)" (there are 30 countries with the red-blue-white 337 combination; see the list in the Supporting Information section), 338 "What is the most populated molecule?" (sulfur monoxide 339 corresponding to the Chinese flag) or "What is the molecule 340 with the higher GDP?". According to the level targeted, and as a 341 variation for the postgame discussion, a list of some of the 342 countries/capitals/molecules can be proposed in front of 343 molecular flags to create a matching game. Whatever the results 344 of the game, the objective remains to practice basic knowledge of 345 world flags and manipulation of the CPK model representation. 346 Students from two separate courses used the game activity and 347 were surveyed after the activity with responses based on the 348 Likert $^{75}$ scale (Figure 7). The response rate was 95\%. In general, 349 all statements showed high levels of agreement ("agree" and 350 "strongly agree"), ranging from $62.1 \%$ to $93.1 \%$ of those 351 surveyed.

352 A majority of students (89.7\%) enjoyed the use of "Fun with 353 Flags" in the courses and thought it was attractive and helped 354 capture their attention $(86.2 \%)$ while $81.6 \%$ also agreed that 355 using this game helped them make connections between the 356 theoretical aspects of courses in geography (69\%), chemistry $357(90.8 \%)$, and geopolitics (69.0\%). Fewer students $(66.7 \%)$

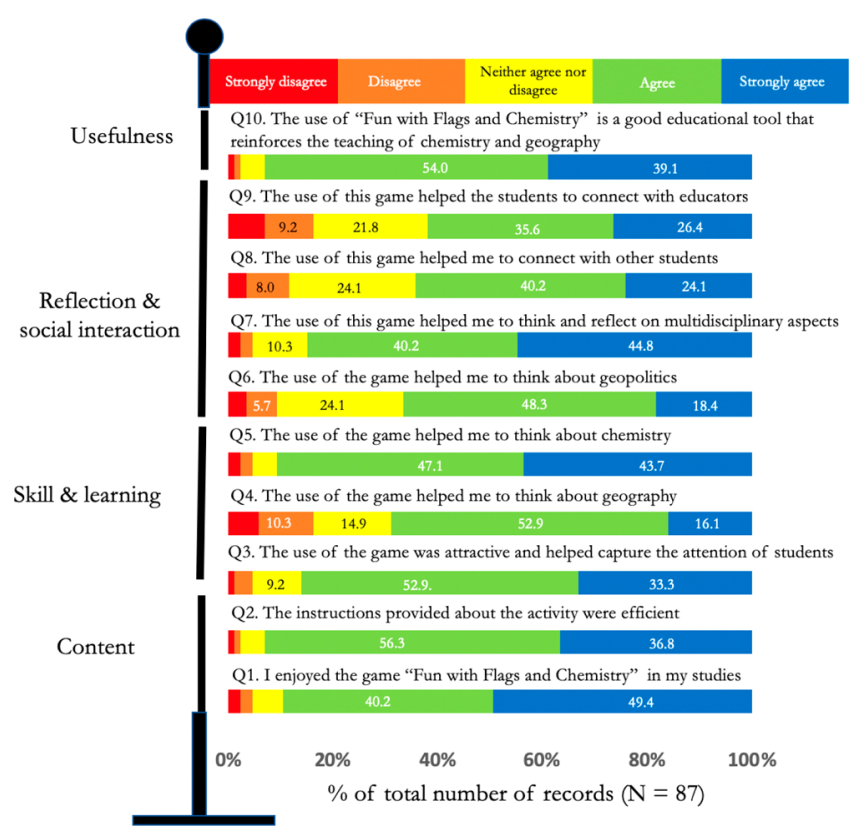

Figure 7. Student responses relating to the use of "Fun with Flags and Chemistry". Total number of respondents $=87$ (academic year 2019/ 2020).

agreed that this activity helped them to develop a multi- 358 disciplinary outlook.

It is worth noting that a majority thought that this activity 360 helped them to connect with other students (64.4\%) and also 361 with educators (62.1\%). Finally, a large majority (93.1\%) think 362 that "Fun with Flags and Chemistry" is an excellent educational 363 tool that can be used to practice chemistry and geography 364 simultaneously. Using "Fun with Flags and Chemistry" is thus 365 beneficial for the classroom because it creates engaging links 366 between chemical concepts and geography, and between 367 educators' and students' interests. The objective is to connect 368 the student's knowledge in the two disciplines and to initiate 369 discussions/debate on geopolitical aspects of both. Geography 370 education research has worked hard to remove itself from the 371 common misconception of geography education relating to 372 memorizing (countries, capitals, and state/national flags). Here, 373 the flag identification is not the end of the activity, it is a pretext 374 to practice and manipulate CPK code and to discuss on 375 geopolitics in a recreative environment; it is then an original 376 approach for more discussion on advanced and modern topics. 377

Work can then be extended after the activity to think more 378 deeply about where resources are located, independence of 379 resources, global politics concerning resources, and the future 380 societal challenge linked with the abundance of chemical 381 compounds.

Educators need to be careful to open the boundaries of this 383 activity so as to unleash the students' curiosity to think about 384 facing these future problems. It is also important to leave the 385 students free to search for information on chemistry, geography, 386 or even history during projects/activities using all types of 387 media, recent or not. Finally, combining geography and 388 chemistry promotes critical thinking and develops skills in 389 humanities, which will be important throughout the students' 390 lives. 


\section{CONCLUSION}

393 The objective of this paper is to present an original way to 394 practice chemistry and geography simultaneously. The activity is 395 based on the similarities of color observed in world national flags 396 and in simple molecular models. With some simplifying 397 hypotheses (band flags, approximation of colors, and neglect 398 of coats of arms and symbols), and after a precise analysis of 399 almost 200 national flags, several series of molecular flags have 400 been proposed with several levels of difficulty, from perfect 401 matching of colors, their number, and their order, to imperfect 402 matching considering color matches only. These series were 403 used as a base for a quiz game where the objective was to identify 404 the country corresponding to the molecular flag. The feedback 405 received from students that participated in this exercise has been 406 evaluated and indicates an increase in motivation through such 407 activities and their acceptance as a good multidisciplinary tool. 408 The game was seen as a good exercise for practicing chemistry 409 and geography, breaking down frontiers between disciplines, 410 engaging students, and raising their awareness of the world's 411 challenges. Such a combination of disciplines made it possible to 412 start discussions about locations of resources and geopolitical or 413 societal challenges of the future. The activity helped students to 414 connect together, and to develop their own curiosity and 415 creativity. It could be adapted to regional flags or those of 416 province/state. To conclude, "Fun with Flags and Chemistry", 417 the first ever attempt of chemo-vexillology, offers a wide range of 418 possibilities for involving students in the classroom, from games 419 to critical thinking, and from basic chemistry to human sciences.

\section{ASSOCIATED CONTENT}

\section{SI Supporting Information}

422 The Supporting Information is available at https://pubs.ac$423 \mathrm{~s} .0 \mathrm{rg} /$ doi/10.1021/acs.jchemed.0c00514.

$424 \quad$ List of combination for the representation of the $195 \mathrm{UN}$ 425 nations flags (PDF, DOCX)

\section{$426 \square$ AUTHOR INFORMATION}

\section{Corresponding Authors}

428 Christophe Coudret - Interactions Moleculaires et Réactivité

429 Chimique et Photochimique (IMRCP), Universite de Toulouse,

430 CNRS, UPS, Toulouse 31063, France; $\odot$ orcid.org/0000-

431 0001-7334-5112; Email: coudret@chimie.ups-tlse.fr

432 Nicolas Dietrich - Toulouse Biotechnology Institute (TBI),

433 Universite de Toulouse, CNRS, INRA, INSA, Toulouse 31077,

434 France; $\odot$ orcid.org/0000-0001-6169-3101;

435 Email: nicolas.dietrich@insa-toulouse.fr; ndietrich.com

436 Complete contact information is available at:

437 https://pubs.acs.org/10.1021/acs.jchemed.0c00514

438 Notes

439 The authors declare no competing financial interest.

\section{REFERENCES}

441 (1) Tjoa, A. M.; Tjoa, S. The Role of ICT to Achieve the UN 442 Sustainable Development Goals (SDG). In ICT for Promoting Human 443 Development and Protecting the Environment; Mata, F. J., Pont, A., Eds.; 444 IFIP Advances in Information and Communication Technology; 445 Springer International Publishing: Cham, 2016; pp 3-13, 446 DOI: $10.1007 / 978-3-319-44447-5$ 1.

447 (2) Borthakur, A.; Singh, P. Sustainability Science-below and above 448 the Ground as per the United Nation's Sustainable Development Goals.
In Climate Change and Soil Interactions; Prasad, M. N. V., Pietrzykowski, 449 M., Eds.; Elsevier, 2020; pp 453-471, Chapter 17, DOI: 10.1016/ 450 B978-0-12-818032-7.00017-5.

(3) Petersen, B.; Barnes, J. R. From Hopelessness to Transformation 452 in Geography Classrooms. Journal of Geography 2020, 119 (1), 3-11. 453

(4) Hupy, J. P. Teaching Geographic Concepts Through Fieldwork 454 and Competition. Journal of Geography 2011, 110 (3), 131-135. 455

(5) Anthamatten, P.; Bryant, L. M. P.; Ferrucci, B. J.; Jennings, S.; 456 Theobald, R. Giant Maps as Pedagogical Tools for Teaching 457 Geography and Mathematics. Journal of Geography 2018, 117 (5), 458 183-192.

(6) Massari, S.; Ruberti, M. Rare Earth Elements as Critical Raw 460 Materials: Focus on International Markets and Future Strategies. 461 Resour. Policy 2013, 38 (1), 36-43. 462

(7) Dietrich, N.; Kentheswaran, K.; Ahmadi, A.; Teychené, J.; 463 Bessière, Y.; Alfenore, S.; Laborie, S.; Bastoul, D.; Loubière, K.; Guigui, 464 C.; Sperandio, M.; Barna, L.; Paul, E.; Cabassud, C.; Liné, A.; Hébrard, 465 G. Attempts, Successes, and Failures of Distance Learning in the Time 466 of COVID-19. J. Chem. Educ. 2020, 97, 2448.

467

(8) Alvargonzález, D. Multidisciplinarity, Interdisciplinarity, Trans- 468 disciplinarity, and the Sciences. International Studies in the Philosophy of 469 Science 2011, 25 (4), 387-403.

(9) Wilder, A.; Brinkerhoff, J. D.; Higgins, T. M. Geographic 471 Information Technologies + Project-Based Science: A Contextualized 472 Professional Development Approach. Journal of Geography 2003, 102473 (6), 255-266.

(10) Florentina, M.; Barbu, M. An Inter-Disciplinary Approach in 475 Teaching Geography, Chemistry and Environmental Education. 476 Procedia - Social and Behavioral Sciences 2015, 180, 660-665. 477

(11) Oldakowski, R.; Johnson, A. Combining Geography, Math, and 478 Science to Teach Climate Change and Sea Level Rise. Journal of 479 Geography 2018, 117 (1), 17-28.

(12) Keighren, I. M.; Crampton, J. W.; Ginn, F.; Kirsch, S.; Kobayashi, 481 A.; Naylor, S. N.; Seemann, J. Teaching the History of Geography: 482 Current Challenges and Future Directions. Progress in Human 483 Geography 2017, 41 (2), 245-262.

(13) Hu, S. An Analysis of Humor in The Big Bang Theory from 485 Pragmatic Perspectives. TPLS 2012, 2 (6), 1185.

(14) Whyte, B. On Cartographic Vexillology Cartographica: The 487 International Journal for Geographic Information and Geovisualization 488 2007, 42, 251.

(15) Skluzacek, J. M.; Harper, J.; Herron, E.; Bortiatynski, J. M. 490 Summer Camp To Engage Students in Nutritional Chemistry Using 491 Popular Culture and Hands-On Activities. J. Chem. Educ. 2010, 87 (5), 492 492-495.

(16) Clauss, A. W. Using Popular Culture To Teach Chemistry. J. 494 Chem. Educ. 2009, 86 (10), 1223.

(17) Smiley, S. L. Teaching Cultural Geography with The Amazing 496 Race. Journal of Geography 2017, 116 (3), 109-118. 497

(18) Smiley, S. L.; Post, C. W. Using Popular Music to Teach the 498 Geography of the United States and Canada. Journal of Geography 499 2014, 113 (6), 238-246.

(19) Zainuddin, Z.; Chu, S. K. W.; Shujahat, M.; Perera, C. J. The 501 Impact of Gamification on Learning and Instruction: A Systematic 502 Review of Empirical Evidence. Educational Research Review 2020, 30, 503 100326.

504

(20) Ponce, P.; Meier, A.; Mendez, J.; Peffer, T.; Molina, A.; Mata, O. 505 Tailored Gamification and Serious Game Framework Based on Fuzzy 506 Logic for Saving Energy in Smart Thermostats. J. Cleaner Prod. 2020, 507 262, 121167.

(21) Rodríguez, I.; Puig, A.; Tellols, D.; Samsó, K. Evaluating the 509 Effect of Gamification on the Deployment of Digital Cultural Probes for 510 Children. International Journal of Human-Computer Studies 2020, 137, 511 102395.

(22) Conway, C. J.; Leonard, M. Insulin-Glucagon Interactions: Using 513 a Game To Understand Hormonal Control. J. Chem. Educ. 2014, 91514 (4), 536-540.

(23) Rau, M. A.; Kennedy, K.; Oxtoby, L.; Bollom, M.; Moore, J. W. 516 Unpacking "Active Learning": A Combination of Flipped Classroom 517 
518 and Collaboration Support Is More Effective but Collaboration 519 Support Alone Is Not. J. Chem. Educ. 2017, 94, 1406.

520 (24) Mandavgane, S. Fun with Fluid: An Innovative Assignment in 521 Fluid Mechanics. Education for Chemical Engineers 2020, 30, 40-48. 522 (25) Mavromihales, M.; Holmes, V.; Racasan, R. Game-Based 523 Learning in Mechanical Engineering Education: Case Study of 524 Games-Based Learning Application in Computer Aided Design 525 Assembly. International Journal of Mechanical Engineering Education 526 2019, 47, 156.

527 (26) Hanson, R. M. The Chemical Name Game. J. Chem. Educ. 2002, 52879 (11), 1380.

529 (27) Capps, K. Chemistry Taboo: An Active Learning Game for the 530 General Chemistry Classroom. J. Chem. Educ. 2008, 85 (4), 518.

531 (28) Campbell, S.; Muzyka, J. Chemistry Game Shows. J. Chem. Educ. 532 2002, 79 (4), 458.

533 (29) Sanders, J. R.; Arce-Trigatti, A.; Arce, P. E. Promoting Student 534 Problem-Identification Skills via a Jeopardy-Inspired Game within the 535 Renaissance Foundry. Education for Chemical Engineers 2020, 30, 4953659.

537 (30) Dizon, A. C. O.; An, S.; Lubguban, A. A.; Suppes, G. J. Online 538 Quiz Methods for Remedial Learning in Chemical Engineering. 539 Education for Chemical Engineers 2018, 23, 18-24.

540 (31) Roštejnská, M.; Klímová, H. Biochemistry Games: AZ-Quiz and 541 Jeopardy! J. Chem. Educ. 2011, 88 (4), 432-433.

542 (32) Adair, B. M.; McAfee, L. V. Chemical Pursuit: A Modified Trivia 543 Board Game. J. Chem. Educ. 2018, 95 (3), 416-418.

544 (33) Brydges, S.; Dembinski, H. E. Catalyze! Lowering the Activation 545 Barriers to Undergraduate Students' Success in Chemistry: A Board 546 Game for Teaching Assistants. J. Chem. Educ. 2019, 96 (3), 511-517. 547 (34) Kucukkal, T. G.; Kahveci, A. PChem Challenge Game: 548 Reinforcing Learning in Physical Chemistry. J. Chem. Educ. 2019, 96 549 (6), 1187-1193.

550 (35) Stojanovska, M. Celebrating the International Year of Periodic 551 Table with Chemistry Educational Games and Puzzles. Chemistry 552 Teacher International 2020, in press.

553 (36) Costa, M. J. CARBOHYDECK: A Card Game To Teach the 554 Stereochemistry of Carbohydrates. J. Chem. Educ. 2007, 84 (6), 977. 555 (37) da Silva Júnior, J. N.; Santos de Lima, P. R.; Sousa Lima, M. A.; 556 Monteiro, Á. C.; Silva de Sousa, U.; Melo Leite Júnior, A. J.; Vega, K. B.; 557 Alexandre, F. S. O.; Monteiro, A. J. Time Bomb Game: Design, 558 Implementation, and Evaluation of a Fun and Challenging Game 559 Reviewing the Structural Theory of Organic Compounds. J. Chem. 560 Educ. 2020, 97 (2), 565-570.

561 (38) Battersby, G. L.; Beeley, C.; Baguley, D. A.; Barker, H. D.; Broad, 562 H. D.; Carey, N. C.; Chambers, E. S.; Chodaczek, D.; Blackburn, R. A. 563 R.; Williams, D. P. Go Fischer: An Introductory Organic Chemistry 564 Card Game. J. Chem. Educ. 2020, 97, 2226.

565 (39) Dietrich, N. Chem and Roll: A Roll and Write Game To Illustrate 566 Chemical Engineering and the Contact Process. J. Chem. Educ. 2019, $56796,1194$.

568 (40) Iribe, J.; Hamada, T.; Kim, H.; Voegtle, M.; Bauer, C. A. Rolling 569 the Dice: Modeling First- and Second-Order Reactions via Collision 570 Theory Simulations in an Undergraduate Laboratory. J. Chem. Educ. $5712020,97,764$.

572 (41) Pippins, T.; Anderson, C. M.; Poindexter, E. F.; Sultemeier, S. 573 W.; Schultz, L. D. Element Cycles: An Environmental Chemistry Board 574 Game. J. Chem. Educ. 2011, 88 (8), 1112-1115.

575 (42) Martín-Lara, M. A.; Calero, M. Playing a Board Game to Learn 576 Bioenergy and Biofuels Topics in an Interactive, Engaging Context. J. 577 Chem. Educ. 2020, 97, 1375.

578 (43) Azizan, M. T.; Mellon, N.; Ramli, R. M.; Yusup, S. Improving 579 Teamwork Skills and Enhancing Deep Learning via Development of 580 Board Game Using Cooperative Learning Method in Reaction 581 Engineering Course. Education for Chemical Engineers 2018, 22, 1-13. 582 (44) Triboni, E.; Weber, G. MOL: Developing a European-Style 583 Board Game To Teach Organic Chemistry. J. Chem. Educ. 2018, 95 (5), $584791-803$.

585 (45) da Silva Júnior, J. N.; Uchoa de, D. E. A.; Sousa Lima, M. A.; 586 Monteiro, A. J. Stereochemistry Game: Creating and Playing a Fun
Board Game To Engage Students in Reviewing Stereochemistry 587 Concepts. J. Chem. Educ. 2019, 96 (8), 1680-1685.

(46) Mewborne, M.; Mitchell, J. T. Carcassonne: Using a Tabletop 589 Game to Teach Geographic Concepts. Geography Teacher 2019, 16 (2), 590 $57-67$.

(47) Miller, J. L.; Wentzel, M. T.; Clark, J. H.; Hurst, G. A. Green 592 Machine: A Card Game Introducing Students to Systems Thinking in 593 Green Chemistry by Strategizing the Creation of a Recycling Plant. J. 594 Chem. Educ. 2019, 96 (12), 3006-3013.

595

(48) da Silva Júnior, J. N.; Sousa Lima, M. A.; Sousa, E. H. S.; Oliveira 596 Alexandre, F. S.; Leite Júnior, A. J. M. KinChem: A Computational 597 Resource for Teaching and Learning Chemical Kinetics. J. Chem. Educ. 598 2014, 91 (12), 2203-2205.

599

(49) Grinias, J. P. Making a Game Out of It: Using Web-Based 600 Competitive Quizzes for Quantitative Analysis Content Review. J. 601 Chem. Educ. 2017, 94 (9), 1363-1366.

(50) Nowosielski, D. A. Use of a Concentration Game for 603 Environmental Chemistry Class Review. J. Chem. Educ. 2007, 84 (2), 604 239.

(51) Silva, D. M.; Ribeiro, C. M. R. Analogue Three-Dimensional 606 Memory Game for Teaching Reflection, Symmetry, and Chirality to 607 High School Students. J. Chem. Educ. 2017, 94 (9), 1272-1275. 608

(52) da Silva Júnior, J. N.; Sousa Lima, M. A.; Silva de Sousa, U.; do 609 Nascimento, D. M.; Melo Leite Junior, A. J.; Vega, K. B.; Roy, B.; 610 Winum, J.-Y. Reactions: An Innovative and Fun Hybrid Game to 611 Engage the Students Reviewing Organic Reactions in the Classroom. J. 612 Chem. Educ. 2020, 97 (3), 749-753.

613

(53) Dietrich, N. Escape Classroom: The Leblanc Process-An 614 Educational "Escape Game. J. Chem. Educ. 2018, 95 (6), 996-999. 615

(54) Estudante, A.; Dietrich, N. Using Augmented Reality to 616 Stimulate Students and Diffuse Escape Game Activities to Larger 617 Audiences. J. Chem. Educ. 2020, 97, 1368.

(55) Clapson, M. L.; Gilbert, B.; Mozol, V. J.; Schechtel, S.; Tran, J.; 619 White, S. ChemEscape: Educational Battle Box Puzzle Activities for 620 Engaging Outreach and Active Learning in General Chemistry. J. Chem. 621 Educ. 2020, 97 (1), 125-131.

(56) Peleg, R.; Yayon, M.; Katchevich, D.; Moria-Shipony, M.; 623 Blonder, R. A Lab-Based Chemical Escape Room: Educational, Mobile, 624 and Fun! J. Chem. Educ. 2019, 96 (5), 955-960.

(57) Vergne, M. J.; Simmons, J. D.; Bowen, R. S. Escape the Lab: An 626 Interactive Escape-Room Game as a Laboratory Experiment. J. Chem. 627 Educ. 2019, 96 (5), 985-991.

(58) Yayon, M.; Rap, S.; Adler, V.; Haimovich, I.; Levy, H.; Blonder, 629 R. Do-It-Yourself: Creating and Implementing a Periodic Table of the 630 Elements Chemical Escape Room. J. Chem. Educ. 2020, 97 (1), 132- 631 136.

(59) Monnot, M.; Laborie, S.; Hébrard, G.; Dietrich, N. New 633 Approaches to Adapt Escape Game Activities to Large Audience in 634 Chemical Engineering: Numeric Supports and Students' Participation. 635 Education for Chemical Engineers 2020, 32, 50.

(60) Vergne, M. J.; Smith, J. D.; Bowen, R. S. Escape the (Remote) 637 Classroom: An Online Escape Room for Remote Learning. J. Chem. 638 Educ. 2020, 97, 2845.

(61) D’Angelo, J. G. Choose Your Own "Labventure": A Click- 640 Through Story Approach to Online Laboratories during a Global 641 Pandemic. J. Chem. Educ. 2020, 97 (9), 3064-3069. 642

(62) Dewar, P. D. Red, White, Blue, and Yellow Chemistry. J. Chem. 643 Educ. 1992, 69 (7), 572.

(63) Chanteau, S. H.; Ruths, T.; Tour, J. M. Arts and Sciences Reunite 645 in Nanoput: Communicating Synthesis and the Nanoscale to the 646 Layperson. J. Chem. Educ. 2003, 80 (4), 395.

(64) Sakai, T.; Nagao, Y.; Nakamura, Y.; Mori, Y. Methanolysis of the 648 Cyclic Acetal Function of NanoKid Catalyzed by NanoGoblin, the 649 Pyridinium Salt of Tetracyanocyclopentadienide. ACS Omega 2017, 2650 (11), 8543-8549.

(65) Shirai, Y.; Osgood, A. J.; Zhao, Y.; Kelly, K. F.; Tour, J. M. 652 Directional Control in Thermally Driven Single-Molecule Nanocars. 653 Nano Lett. 2005, 5 (11), 2330-2334. 
655 (66) Nishino, T.; Martin, C. J.; Takeuchi, H.; Lim, F.; Yasuhara, K.; 656 Gisbert, Y.; Abid, S.; Saffon-Merceron, N.; Kammerer, C.; Rapenne, G. 657 Dipolar Nanocars Based on a Porphyrin Backbone. Chem. - Eur. J. 2020, 65826 (52), 12010.

659 (67) Corey, R. B.; Pauling, L. Molecular Models of Amino Acids, 660 Peptides, and Proteins. Rev. Sci. Instrum. 1953, 24 (8), 621-627.

661 (68) Koltun, W. L. Space Filling Atomic Units and Connectors for 662 Molecular Models. US 3170246 A, February 23, 1965.

663 (69) Turner, K. L. A Cost-Effective Physical Modeling Exercise To 664 Develop Students' Understanding of Covalent Bonding. J. Chem. Educ. 665 2016, 93 (6), 1073-1080.

666 (70) Grumman, A. S.; Carroll, F. A. 3D-Printing Electron Density 667 Isosurface Models and High-Resolution Molecular Models Based on 668 van Der Waals Radii. J. Chem. Educ. 2019, 96 (6), 1157-1164.

669 (71) Holme, T. A. Journal of Chemical Education Call for Papers: 670 Special Issue on Insights Gained While Teaching Chemistry in the 671 Time of COVID-19. J. Chem. Educ. 2020, 97 (5), 1226-1227.

672 (72) Mingst, K.; Karns, M. P. The United Nations In The Post-Cold War 673 Era, 2nd ed.; Routledge, 2019.

674 (73) Raeside, R. Flags of the World, 2012. https://www.crwflags.com/ $675 \mathrm{fotw} /$ flags/index.html.

676 (74) Croswell, K. The Alchemy of the Heavens: Searching for Meaning in 677 the Milky Way; Anchor Books, 1996.

678 (75) Likert, R. A Technique for the Measurement of Attitudes. 679 Archives of Psychology 1932, 22140, 55-55. 